\title{
Effects of an exercise programme with people living with HIV: research in a disadvantaged setting
}

\author{
Clemens Ley, Lloyd Leach, María Rato Barrio and Susan Bassett
}

\begin{abstract}
This study aimed to analyse the physical health effects of a community based 10-week physical activity programme with people living with HIV. It was developed, implemented and evaluated in a disadvantaged community in South Africa. A pre-post research design was chosen. Major recruitment and adherence challenges resulted in a small sample. Among the 23 participants who took part in both baseline and final testing, compliant participants $(n=12)$ were compared to non-compliant participants $(n=11)$. Immunological (CD4, viral load), anthropometric (height, weight, skinfolds and waist to hip ratio), muscular strength (h1RM) and cardiopulmonary fitness (time on treadmill) parameters were measured. The compliant and non-compliant groups were not different at baseline. Muscular strength was the parameter most influenced by compliance with the physical activity programme $(F=4.516, p=0.047)$. Weight loss and improvement in cardiopulmonary fitness were restricted by the duration of the programme, compliance and influencing factors (e.g. nutrition, medication). The increase in strength is significant and meaningful in the context, as the participants' goals were to look healthy and strong to avoid HIV related stigma. The improvements in appearance were a motivational factor, especially since the changes were made visible in a short time. Practical implications for health promotion are described. More research contextualised in disadvantaged settings is needed.
\end{abstract}

\section{Introduction}

Over the past decades evidence has emerged regarding the benefits of exercise on physical functioning, cardio- pulmonary fitness, metabolism and muscle endurance of people living with HIV (Smith et al. 2001, Driscoll et al. 2004, O'Brien et al. 2004, Farinatti et al. 2010, O'Brien et al. 2010). These effects are important in the light of HIV-associated diseases, including lipodystrophy, body changes, the side effects of antiretroviral medication and comorbidities. In addition, improvements in cardiopulmonary fitness and functional capacities have an important role in the management of daily life, wellbeing and quality of life of people living with HIV (Mutimura et al. 2008, Myburgh and De Bruto 2008, Gomes et al. 2010, Gomes et al. 2013a).

Mos reviewed studies used individualised exercise training over a period of 10 to 12 weeks. Aerobic training was used, mainly on a treadmill or cycle ergometer, with a 
moderate intensity workload of $40 \%$ to $60 \%$ of $\mathrm{VO}_{2} \max$, although some studies used a moderate to high intensity of $60 \%$ to $85 \%$ of $\mathrm{VO}_{2} \max$ (Stringer 2004, O'Brien et al. 2010). Results of a Cochrane review indicated that regular progressive resistance training is safe, and improves the physical factors of strength, weight and body composition, and may also contribute to an improvement in cardiopulmonary fitness and psychological status of adults living with HIV (O'Brien et al., 2004). Thus a combination of aerobic and progressive resistance training is widely recommended (Robinson et al. 2011, Yahiaoui et al. 2011). However, many questions remain unanswered, such as how to achieve these physical and physiological effects in the specific context of people living with HIV in disadvantaged communities. There is a paucity of research that explores different types of physical activities including, for example, sport and games that are popular and accessible in many communities around the world (Ley and Rato Barrio 2012, Gomes et al. 2013b). Besides the physiological effects of aerobic and progressive resistance training, the popularity and group dynamics of sport and games could facilitate better access to physical activity and adherence to a physically active lifestyle. Few authors have discussed the opportunities that these activities provide for people living with HIV (Florijn 1996, Rojas Salcedo 2001, Ferez and Luauté 2008, Ley and Rato Barrio 2012).

In addition, few studies have been done in Africa (Ley and Rato Barrio 2012), where the main burden of HIV is found. HIV infection is one of the four major burdens of disease in South Africa, with an estimated prevalence at 17.8\% among 15-49-year-olds (UNAIDS 2010). "Conclusions drawn from women [with HIV] living in a Western society will not necessarily reflect those found in sub-Saharan Africa where socioeconomic factors and ethnicity could influence body composition changes" (Myburgh and De Bruto 2008: 340, cf. Chopra and Ford 2005). In addition, some authors argue that "obesity is valued in many African cultures because it is associated with dignity, wealth and being treated well by one's husband, and weight loss is regarded as a source of stigma and a sign of disease, in particular HIV/AIDS" (Stern et al. 2010: 2, cf. Ezekiel et al. 2009, Matoti-Mvalo and Puoane 2011). Limited space and impoverished living conditions in disadvantaged communities do not offer a favourable environment for practising physical activity (McVeigh et al. 2004) and physical activity levels of people living with HIV are low in South Africa (Kinsey et al. 2007, 2008). At the same time, "exercise training is an inexpensive and efficacious strategy for improving QoL in HIV+ African subjects, which may improve HAART [Highly Active Anti-Retroviral Treatment] adherence and treatment initiatives in resource- limited areas of sub-Saharan Africa" (Mutimura et al. 2008: 377). There is a vast gap in the research contextualised in Africa, especially in disadvantaged communities (Ley and Rato Barrio 2012).

Therefore the purpose of this study was to determine the health effects of a community based physical activity programme on people living with HIV contextualised in a disadvantaged context, as opposed to a laboratory setting. In addition, it aimed to analyse challenges encountered in undertaking the research and intervention programme. 


\section{Methods \\ Design}

A pre-post test design was chosen to evaluate the effects of the 10-weeks exercise programme. A disadvantaged urban setting on the outskirts of Cape Town, South Africa, was selected to conduct the research at community level with people living with HIV. Because of the social stigma related to HIV in this community, the research project could not be publicised as a project for people living with HIV. Instead, recruitment was done through advertising for a health promotion programme through institutions working in the field, such as community clinics, non-governmental organisations (NGOs) and HIV programmes. All participants recruited for the programme were asked to take part in the research. The recruited sample size was too small to establish a control group, as had been planned.

\section{Participants}

Study inclusion criteria were participants had to be HIV-positive and willing to participate in the exercise programme. Exclusion criteria were acute infection (e.g. active tuberculosis), pregnancy, uncontrolled hypertension, and any other disease or infection that was contra-indicated for sport and exercise participation. No selection to the project was based on HIV stage, disease progression, medication use or associated illnesses or physiological changes (e.g. lipodystrophy).

Although regular reminders were sent to the 50 persons who were initially interested, only 36 arrived for baseline testing. Of these, three were without HIV infection but were allowed to participate in all activities together with the other participants (to avoid stigmatisation and to secure the support of friends), but these participants were omitted from the data analysis. Another five of the participants were excluded from the project because of acute tuberculosis $(n=1)$, a recent operation $(n=1)$, pregnancy $(n=1)$ and uncontrolled high blood pressure $(n=2)$. Of the 28 HIV-positive participants remaining, all were asked to participate in the final measurement independent of their compliance. Five participants were not available for the final testing, because of relocating to another suburb $(n=3)$ and not being contactable $(n=2)$. The remaining 23 participants varied in age between 20 and 44 years $(M \pm \mathrm{SD}=30.00$ \pm 7.44 years). Of these, 3 were male and 20 were female.

\section{Intervention}

Special efforts were made to make the intervention suitable and meaningful for the participants and pertinent to the specific setting in which it occurred. In a participatory process, the participants discussed their preferences and needs. Two different programme settings were identified. Participants in Group A $(n=11)$ preferred to train individually. Reasons for this were mainly time availability, but doubts about the group dynamics and confidentiality in group settings were issues identified as potentially conflicting. A gym with qualified trainers was used. The trainers were blinded to the research goals and HIV status of the participants.

The participants in Group B $(n=12)$ preferred to train in a group setting. The programme setting for this group was a school within the disadvantaged community that was made available in the afternoons. The activities in both groups were based 
on the same training principles, and included aerobic exercises (running/walking, stepper, etc.), progressive resistance training and stretching. In Group B, in addition, a sport or a game was played in each session. The workload in Group B was measured during some sessions with a Polar Team $2^{\circledR}$ heart rate monitor, and a record of the exercises, intensity, repetitions, duration and exertion of each session were kept by using a session sheet in both groups.

Although the time of a training session in Group B (approximately 90 minutes) was longer than in Group A (60-70 minutes), the workload was similar for both groups. This was mainly because group dynamics were slower than individual training (e.g. more time was spent changing from one exercise to another, waiting for everyone to finish the exercise or allowing discussions among participants between activities) and the type of physical activity chosen. The games and sports played were less strenuous per time unit than the more focused individual training. The intensity of both programmes was moderate (ranging from $40 \%$ to $70 \%$ of estimated maximal heart rate) and followed a progressive overload. All participants were asked to participate 3 times a week for a period of at least 10 weeks. Follow-up interventions and research are ongoing.

\section{Research procedures}

After ethical clearance had been obtained from the University Research Committee (Reg. $\mathrm{N}^{\mathrm{O}} 11 / 4 / 17$ and $11 / 4 / 18$ ) and the Municipality Health Committee (Reg. $\mathrm{N}^{\mathrm{O}}$ : 10258), participants were recruited through the collabo- rating community clinic, health forum, NGOs and HIV programmes. They were informed about the research and exercise intervention by oral presentation and an information sheet. They were given the opportunity to participate in the exercise intervention without participating in the research study or to participate only partially in the research project (e.g. not giving blood) without the other participants knowing of their decision. All information and research instruments were made available in isiXhosa and English. Reversetranslation was used to check the accuracy of the questionnaires. Bilingual facilitators and translators were present at all times for the participants. All recruited persons gave their informed consent. No payments were made to the participants. Each participant was given a code, and the identifiers were safeguarded. None of the participants were asked to reveal their HIV status except to the medical doctor and main researcher. The research assistants were likewise blinded to the HIV status of the participants. All testing was done at a tertiary institution. At the end of the programme, feedback was given individually to the participants.

A medical doctor examined the participants, checked for signs and symptoms, assessed their health and medication backgrounds, and recommended full, partial or no participation in the project. The following measurements were taken at baseline and after the 10-week intervention, independent of compliance.

\section{Measures}

A blood sample was drawn by a nurse and sent to a national health laboratory for analysis. The tetrachrome T-Cell subsets test (Immunophenotyping per marker) was used to analyse $\mathrm{CD}_{4}$ count (cells/ $\mu \mathrm{l}$ ) and percentage (\%); the EasyQ HIV viral load 
test (Abbott m200o RealTime HIV-1 assay) was used to measure HIV viral load (RNA cps/ml).

Anthropometric measurements were taken by trained research assistants. Weight and height were measured with a beam balance scale and stadiometer, and body mass index (BMI) was calculated. Waist circumference at the narrowest point and maximum hip circumference were measured with an anthropometric tape measure, and waist- tohip ratio (WHR) was calculated. Thickness of three central (subscapula, suprariliac, vertical abdomen) and four peripheral skinfolds (triceps, biceps, thigh and medial calf) were measured with a Harpenden skinfold caliper, to the nearest $1.0 \mathrm{~mm}$.

A submaximal graded exercise test using the modified Bruce protocol was conducted on a treadmill, where the participants were stopped at $85 \%$ of estimated maximal heart rate. Time on treadmill (fatigue) was measured and $\mathrm{VO}_{2}$ max was estimated. Heart rate was recorded every minute, while blood pressure and the Borg rating of perceived exertion were taken every three minutes. Participants were continuously monitored during testing, by an electrocardiogram (ECG).

Strength test was measured on a leg-press machine. Hypothetic-one-repetitionmaximum testing (h1RM) was used to avoid maximal static pressure and forced respiration (Baumann 2008). Instructions from Giessing (2003) were followed to calculate maximal strength performance according to a validated table.

During the period of the intervention, exercise compliance was monitored in both groups by taking a register of attendance. Non-compliance was attributed to a participant when she/he took part in the programme on average for less than once a week, that means, less than one-third of the total number of sessions.

In addition, qualitative data were captured during the programme planning, implementation and evaluation period, using participatory observation (field diaries), semi-structured interviews with all participants (recorded and transcribed) and group discussions (extensive notes). The data were analysed according to the quantitative results.

\section{Data management and analysis}

Data on the treadmill, ECG, and Polar Team $2{ }^{\circledR}$ measurements were recorded using a computer, and through an exercise log sheet. A secure database was created and the data were analysed with the Statistical Package for the Social Sciences version 18.

Descriptive analysis was used to describe the sample. Categorical baseline measures were compared, using the chi-square test. Continuous baseline measures were compared between the compliant and non-compliant groups, and between the two different intervention groups, using $t$-tests. When the data were not normally distributed, the Mann-Whitney $U$-test was used. The $t$-test for paired samples was used to compare initial and final measurements in the compliant and in the noncompliant group separately. 
Analysis of covariance (ANCOVA), with change from baseline as the dependent variable and compliance as the independent variable (and baseline values as the covariates), was used to determine the influence of compliance.

\section{Results}

The marital status of the participants ranged from single $(n=13)$, married $(n=5)$, separated $(n=2)$ to widowed $(n=1)$. A total of 19 indicated isiXhosa as their home language, 1 indicated English and 2 indicated other languages. Sixteen were unemployed, three were working (paid) part-time and four were working (paid) full time. CD4+ cell count ranged from 155 to 1315 cells $/ \mu \mathrm{l}(M \pm \mathrm{SD}=535.32 \pm 256.06$ cells $/ \mu \mathrm{l})$ and $\mathrm{CD} 4+$ percentage from $9-41 \%(M \pm \mathrm{SD}=25.77 \pm 9.40 \%)$. At baseline, 13 (56.5\%) of the 23 participants were taking antiretroviral medica- tion and their viral load was undetectable. The viral load of the other participants was between 1751 and $152063 \mathrm{RNA} \mathrm{cps} / \mathrm{ml}(M \pm \mathrm{SD}=16676.5 \pm 36729.41 \mathrm{cps} / \mathrm{ml})$. The participants were medically classified into World Health Organization (WHO) stage I $(n=10)$; WHO stage II $(n=6)$; WHO stage III $(n=5)$; and WHO stage IV $(n=2)$.

\section{Differences between the two intervention groups at baseline}

No significant differences at baseline were found between the two intervention groups with regard to the WHO stage, based on the examination of the medical doctor (chi-square $=2.561 ; p=0.464)$, the $\mathrm{CD} 4$ cell count $(U=44.5 ; p=0.307)$ and CD4 percentage $(U=56 ; p=0.792)$. In the groups A and $\mathrm{B}$, respectively $36 \%$ and $75 \%$ of the participants were taking ARV medication (chi-square $=3.486 ; p=0.062$ ). Group A was on average slightly younger than Group B $(t=-2.431 ; p=0.024)$. There were no significant differences between the groups for any of the physical parameters measured.

\section{Differences between compliers and non-compliers at baseline}

Group A was significantly less compliant (chi-square $=9.763 ; p=$ 0.002), having only two participants who participated in at least one-third of all the training sessions over the 10-week period. Reasons given for non-compliance were mainly challenges in time management, illness, HIV-related stigma, and competing priorities, like caring of children, getting financial support from various sources, work and/or studies.

No significant differences were found regarding WHO stage (chi-square $=4.432 ; p=$ o.218), CD4 count ( $U=52 ; p=0.598)$ and $\mathrm{CD} 4$ percentage $(U=45.5 ; p=0.338)$. Ten of the 12 participants in the compliant group were on ARV medication compared to only 3 of the 11 in the non-compliant group (chi-square $=6.418 ; p=0.011$ ). Compliers were slightly older $(t=-2.039 ; p=0.054)$.

Physical parameters at baseline were not significantly different in the compliant and non-compliant groups (see Table 1). 


\section{Differences between pre- and post-test according to compliance}

Since only two participants complied with the programme in Group A, it was not possible to compare changes from initial to final measurement according to the two intervention groups.

Compliance with the physical activity programme had no significant influence on changes in CD4 count $(F=2.846 ; p=0.109)$ and percentage $(F=0.161 ; p=0.693)$, using ANCOVA. In addition, the heterogeneity in initial CD4 count, influencing factors, such as disease progression, antiretroviral medication, and the small sample size limited the data analysis and results.

Compliance had a significant influence on the changes in strength. In the compliant group, strength improved significantly more than in the non-compliant group (see Table 1). The time on the treadmill and the estimated $\mathrm{VO}_{2} \max$ increased from baseline. However, compliance had no significant influence in the ANCOVA.

Compliance with the exercise programme had no significant influence on changes in anthropometric measures, except in the case of the peripheral skinfolds sum, showing more decrease in the non-compliant group. Generally, $(p=0.087)$ BMI decreased in the compliant group and increased in the non-compliant group (Table 1).

\section{Differences between pre- and post-test in the compliant group}

Analysing for change in each group separately, using paired $t$-test, a significant decrease in the peripheral skinfold sum $(t=-3.283 ; p=0.008)$ was observed as the only difference between baseline and final measurements in the non-compliance group, whereas in the compliant group endurance (time on treadmill and estimated $\mathrm{VO}_{2}$ max: $t=2.845 ; p=0.017$ ) and muscle strength (h1RM: $t=2.272 ; p=0.044$ and strength/body ratio: $t=2.755 ; p=0.019$ ) improved significantly.

\section{Discussion}

This study hypothesised that there would be an improvement in physical health parameters through a 10-week physical activity programme with people living with HIV in a disadvantaged community.

A significantly greater improvement in muscular strength was observed in the compliant group. This result is particularly meaningful for the participants in the described context. The improvements in muscular strength were visible much faster than other improvements and therefore were a motivating factor for the participants. The improvement in strength had a role to play not only in improving physical function and wellbeing, but also had psychosocial importance, namely in avoiding being stigmatised. Appearing physically thin is often associated with being unhealthy and infected with HIV (Stern et al. 2010, Matoti-Mvalo and Puoane 2011). 
Table 1: Analysis of covariance (ANCOVA) of changes on physical parameters according to compliance

\begin{tabular}{|c|c|c|c|c|c|c|c|c|c|c|c|c|}
\hline \multirow[b]{2}{*}{ Information } & \multicolumn{5}{|c|}{ Compliers } & \multicolumn{5}{|c|}{ Non-compliers } & \multirow[b]{2}{*}{$F$} & \multirow[b]{2}{*}{$p$} \\
\hline & $n$ & \multicolumn{2}{|c|}{ Pre-test } & \multicolumn{2}{|c|}{ Post-test } & $n$ & \multicolumn{2}{|c|}{ Pre-test } & \multicolumn{2}{|c|}{ Post-test } & & \\
\hline Weight (kg) & 12 & 75.3 & $(13.94)$ & 74.2 & $(15.24)$ & 11 & 68.3 & (15.36) & 69.1 & $(15.43)$ & 2.473 & 0.131 \\
\hline$\Sigma$ Central skinfolds (mm) & 12 & 67.7 & (30.69) & 67.9 & $(34.80)$ & 11 & 83.8 & (38.18) & 75.8 & (34.15) & 1.078 & 0.312 \\
\hline$\Sigma$ Peripheral skinfolds (mm) & 11 & 104.0 & $(46.03)$ & 99.6 & $(41.32)$ & 11 & 107.7 & $(41.38)$ & 88.5 & $(30.75)$ & 6.767 & $0.018^{*}$ \\
\hline Waist girth $(\mathrm{cm})$ & 11 & 81.8 & $(9.23)$ & 81.5 & $(10.76)$ & 11 & 79.6 & $(13.6)$ & 80.9 & (14.53) & 1.041 & 0.320 \\
\hline Time on treadmill (min) & 11 & 11.5 & (3.31) & 12.8 & $(2.65)$ & 10 & 11.4 & $(2.96)$ & 12.0 & $(2.18)$ & 2.065 & 0.168 \\
\hline Est. $\mathrm{VO}_{2} \max (\mathrm{ml} / \mathrm{kg}$ per $\mathrm{min})$ & 11 & 22.3 & (7.71) & 25.4 & $(6.16)$ & 10 & 22.1 & $(6.89)$ & 23.4 & $(5.07)$ & 2.065 & 0.168 \\
\hline Strength $(\mathrm{kg})$ & 12 & 134.0 & $(43.88)$ & 169.5 & $(46.75)$ & 10 & 110.7 & (34.95) & 120.3 & $(39.06)$ & 4.516 & $0.047^{\star}$ \\
\hline Strength/body ratio & 12 & 1.81 & $(0.59)$ & 2.33 & $(0.67)$ & 10 & 1.69 & $(0.47)$ & 1.86 & $(0.57)$ & 3.384 & 0.081 \\
\hline
\end{tabular}

Social-cultural beliefs and fear of disclosure were often named as profoundly influencing factors, and must be considered in the context of HIV (Mahajan et al. 2008). Besides aiming to reduce body weight, particularly central fat weight, the main goal of the participants was to improve appearance, and to look good, healthy and strong. In that sense, their goals were in line with the recommendations of the stateof-the-art, which are to combine aerobic and progressive resistance training (O'Brien et al. 2004, Robinson et al. 2007, Hand et al. 2009, Lazzarotto et al. 2010, O'Brien et al. 2010, Souza et al. 2011, Yahiaoui et al. 2011).

Fatigue (time on the treadmill and estimated $\mathrm{VO}_{2} \mathrm{max}$ ) increased slightly from baseline to post-test in the compliant group, although it was not significant in the ANCOVA. Participation in the intervention programme was probably too short and too irregular. In addition, compliance was defined in this study as an average participation of at least one session per week in the intervention programme. Only two participants attained the recommended level of exercising at least three times a week. Correspondingly, changes in body weight and BMI did not reach significance level.

Another major influencing factor with regard to weight management was nutrition, which was a shortcoming of the programme. Numerous discussions arose amongst the participants concerning the access to healthy food in the community and recommendations on nutrition were given informally by the facilitators. However, this did not constitute a formal intervention strategy of the programme. Some participants said that they knew what to eat and that nutrition is important when taking ARV medication, but that healthy food was too expensive to buy and was often inaccessible in their community. They could not even afford to buy foods such as fruits and vegetables, which was particularly disconcerting. Other studies in the same environment confirm these challenges (Temple et al. 2011, Stupar et al. 2012). Various authors recommend combining physical activity with nutrition programmes, and call for more holistic, community-based and multi-level interven- tions (Whitelaw et al. 2001, Biddle and Mutrie 2008, Weiss et al. 2011, Ley and Rato Barrio 2012).

Although a randomised controlled trial was planned at the outset of the study, this was not possible during the implementation phase of the study because of challenges in recruitment and compliance. These challenges included fear of disclosure and stigmatisation, mistrust towards the research endeavour, poor time management, people regularly changing telephones, altering living and workplaces, and the fact 
that the research and physical exercise programme competed with the participants' immediate priorities in social security in their struggle for daily living.

Participant-orientated sampling was used that identified two groups with different needs and priorities. A comparison between the two groups was limited by the disproportional lack of compliance in Group A. Quite a heterogeneous group of people participated in the physical activity programme, representing an extensive diversity with regard to $\mathrm{CD} 4$ count, disease progression, medication use, and signs and symptoms (e.g. lipodystrophy). These factors have a complex influence on body changes, weight loss or gain, and body composition (Caron-Debarle et al. 2010). Therefore determining precisely the effects of the 10-week physical activity programme and control- ling for the influencing factors were particular challenges in this research setting. A heterogeneous group is probably daunting when implementing a physical activity programme in a disadvantaged community (and outside of a structured research setting). Studying an exclusive homogeneous population of people living with HIV might give us a distortion of the reality and might have limited practical implications. However, more intervention research is needed that allows adequate differentiation among the participants living with HIV, their motivations, needs, preferences, health conditions and so on, in their specific social-ecological framework.

In conclusion, muscular strength training may be an important element of physical activity programmes with people living with HIV in disadvantaged communities, to promote health, in addition to being motivational (fast, visible positive outcome) and being coherent with participants' goals. Long-term adherence to physical activity is crucial to achieving further health benefits in a very unstable context. In addition, multidimensional intervention research is needed to control and have an impact on a high variety of influencing factors (including nutrition, medication, stress, social and physical barriers). Participatory processes in assessment, planning, implementation and evaluation are crucial to understanding and differentiating needs and preferences of participants in the specific context and to promote physical activity in a pertinent and meaningful manner. Sociocultural beliefs, fears of disclosure and HIV-related stigma played a major role in participants' goal-setting, motivation and compliance. 


\section{Acknowledgements}

We thank all the participants for their participation, and the community clinic, laboratory, HIV unit, health promoters, nurse, facilitators and research assistants for their support. We are very grateful for the continuous support granted by the Universidad Politécnica de Madrid (UPM). We thank the University of the Western Cape, Programme Dynamic of Building a Better Society (DBBS-VLIR), and the Ministerio de Asuntos Exteriores y de Cooperación-Agencia Española de Cooperación International para el Desarrollo (MAEC-AECID) for supporting the respective post-doctoral fellowships of Clemens Ley and María Rato Barrio.

\section{The authors}

Clemens Ley, PhD, works at the University of Vienna. He teaches and researches in the fields of sport and exercise psychology, exercise and movement therapy and health psychology. His research interests are in sport, development, HIV, trauma, mental illness and psychosocial aspects of rehabilitation.

Lloyd Leach, PhD, is senior lecturer and deputy departmental chairperson at the University of the Western Cape, South Africa. His research interests are in sport and HIV/AIDS, biokinetics, exercise the rehabilitation, as well as health risk behaviours of fire fighters.

María Rato Barrio, $\mathrm{PhD}$, is a Sport Scientist and Anthropologist. She lectures on sport and development, research methods and evaluation. Her research interests are in sport for development, monitoring and evaluation, intercultural processes, and impacts of violence on otherness and urban transformation.

Susan Bassett, PhD, works at the University of the Western Cape, South Africa. Her research interests include exercise for health and wellness, whole body vibration and fitness. 


\section{References}

Baumann FT. 2008. Krafttraining mit Krebspatienten. In: Baumann FT, Schüle K (eds), Bewegungstherapie und Sport bei Krebs. Leitfaden für die Praxis. Köln: Deutscher Ärzte-Verlag. pp.57-73. Biddle SJ, Mutrie N. 2008. Psychology of physical activity: determinants, well-being and interventions (2nd edn). Oxon, UK:Routledge.

Caron-Debarle M, Lagathu C, Boccara F, Vigouroux C, Capeau J. 2010. HIV-associated lipodystrophy: from fat injury to premature aging. Trends in Molecular Medicine 16: 218-229.

Chopra M, Ford N. 2005. Scaling up health promotion interventions in the era of HIV/AIDS: challenges for a rights based approach. Health Promotion International 20: 383-390.

Driscoll SD, Meininger GE, Lareau MT, Dolan SE, Killilea KM, Hadigan CM, LloydJones DM, Klibanski A, Frontera WR, Grinspoon SK. 2004. Effects of exercise training and metformin on body composition and cardiovascular indices in HIV-infected patients. AIDS 18: 465-473.

Ezekiel MJ, Talle A, Juma JM, Klepp K-I. 2009. "When in the body, it makes you look fat and HIV negative": The constitution of antiretroviral therapy in local discourse among youth in Kahe, Tanzania. Social Science \& Medicine 68: 957-964.

Farinatti PTV, Borges JP, Gomes RD, Lima DB, Fleck SJ. 2010. Effects of a supervised exercise program on the physical fitness and immunological function of HIV-infected patients. The Journal of Sports Medicine and Physical Fitness 50: 511-518.

Ferez S, Luauté J-P. 2008. L'activité physique et sportive comme outil médicopsychologiqueé? étude de l'offre de pratiques en direction des personnes infectées par le VIH. Annales Médico- psychologiques, revue psychiatrique 166: 847849.

Florijn YCK. 1996. Sport als therapeutische Maßnahme bei Menschen mit HIV und AIDS. In: Rieder H, Huber G, Werle J (eds), Sport mit Sondergruppen. Ein Handbuch. Schorndorf: Hofmann. pp 452-455.

Giessing J. 2003. Trainingsplanung und -steuerung beim Muskelaufbautraining. Leistungssport 4: 26-31.

Gomes RD, Borges JP, Lima DB, Farinatti PTV. 2010. Effects of physical exercise in the perception of life satisfaction and immunological function in HIV-infected patients: Non-randomized clinical trial. Revista Brasileira De Fisioterapia 14: 390-395.

Gomes M, Ogalha C, Andrade AM, Brites C. 2013a. A systematic review of effects of concurrent strength and endurance training on the health-related quality of life and cardiopulmonary status in patients with HIV/AIDS. BioMed Research International 2013: 319524). Available at http://dx.doi.org/10.1155/2013/319524.

Gomes M, Conceicao CS, Carvalho VO, Brites C. 2013b. A systematic review of the effects of different types of therapeutic exercise on physiologic and functional measurements in patients with HIV/AIDS. Clinics 68: 1157-1167.

Hand GA, Lyerly GW, Dudgeon WD. 2009. Acquired immune deficiency syndrome (AIDS). In: Durstine J, American College of Sports Medicine (eds), ACSM's exercise management for persons with chronic diseases and disabilities. Champaign, Illinois: Human Kinetics. pp 219-225.

Kinsey K, Chantler I, McVeigh JA, Jordan D, Nowak I. 2007. Aerobic capacity, muscle strength and physical activity levels in a group of HIV positive females. African Journal for Physical, Health Education, Recreation and Dance 13: 414-429. 
Kinsey K, McVeigh JA, Chantler I. 2008. Habitual physical activity levels are positively correlated with CD4 counts in an HIV-positive South African population. African Journal of AIDS Research 7: 237-242.

Lazzarotto AR, Deresz LF, Sprinz E. 2010. HIV/AIDS e Treinamento Concorrente: a Revisão Sistemática. Revista Brasileira De Fisioterapia 16:149-154.

Ley C, Rato Barrio M. 2012. A narrative review of research on the effects of physical activity on people living with HIV and opportunities for health promotion in disadvantaged settings. African Journal of AIDS Research 11: 123-133.

Mahajan AP, Sayles JN, Patel VA, Remien RH, Sawires SR, Ortiz DJ, Szekeres G, Coates TJ. 2008. Stigma in the HIV/AIDS epidemic: a review of the literature and recommendations for the way forward. AIDS 22: S67-S79.

Matoti-Mvalo T, Puoane T. 2011. Perceptions of body size and its association with HIV/AIDS. South African Journal of Clinical Nutrition 24: 40-45.

McVeigh JA, Norris SA, De Wet T. 2004. The relationship between socio-economic status and physical activity patterns in South African children. Acta Pædiatrica 93: 982-988.

Mutimura E, Stewart A, Crowther NJ, Yarasheski KE, Cade WT. 2008. The effects of exercise training on quality of life in HAART-treated HIV-positive Rwandan subjects with body fat redistribution. Quality of Life Research 17: 377-385.

Myburgh KH, De Bruto PC. 2008. Body composition in women with HIV/AIDS: The relevance of exercise. Continuing Medical Education 26: 339-345.

O’Brien K, Nixon S, Glazier R, Tynan A-M. 2004. Progressive resistive exercise interventions for adults living with HIV/AIDS. Cochrane Database of Systematic Reviews 4 (CDoo4248).

O’Brien K, Nixon S, Tynan A-M, Glazier R. 2010. Aerobic exercise interventions for adults living with HIV/AIDS. Cochrane Database of Systematic Reviews 8 (CDo01796).

Robinson FP, Quinn LT, Rimmer JH. 2007. Effects of high-intensity endurance and resistance exercise on hiv metabolic abnormalities: a pilot study. Biological Research For Nursing 8: 177-185.

Rojas Salcedo RI. 2001. Vergleich zwischen den Auswirkungen eines Sport- und eines psychotherapeutischen Programms auf die Lebensqualität HIV-1 positiver Menschen. Regensburg: Roderer Verlag.

Smith BA, Neidig JL, Nickel JT, Mitchell GL, Para MF, Fass RJ. 2001. Aerobic exercise: effects on parameters related to fatigue, dyspnea, weight and body composition in HIVinfected adults. AIDS 15: 693-701.

Souza PML de, Jacob-Filho W, Santarém JM, Zomignan AA, Burattini MN. 2011. Effect of progressive resistance exercise on strength evolution of elderly patients living with HIV compared to healthy controls. Clinics 66: 261-266.

Stern R, Puoane T, Tsolekile L. 2010. An exploration into the determinants of noncommunicable diseases among rural-to-urban migrants in periurban South Africa. Preventing Chronic Disease 7: A131.

Stringer WW. 2004. HIV and AIDS. In: LeMura L, Von Duvillard SP (eds), Clinical exercise physiology: application and physiological principles. Philadelphia: Lippincott Williams \& Wilkins. pp 455-482.

Stupar D, Eide WB, Bourne L, Hendricks M, Iversen PO, Wandel M. 2012. The nutrition transition and the human right to adequate food for adolescents in the Cape Town metropolitan area: Implications for nutrition policy. Food Policy 37: 199-206. 
Temple NJ, Steyn NP, Fourie J, De Villiers A. 2011. Price and availability of healthy food: a study in rural South Africa. Nutrition 27: 55-58.

U AIDS (Joint United Nations Programme on HIV/AIDS). 2010.

UNAIDS report on the global AIDS epidemic. Geneva: UNAIDS.

Weiss SM, Tobin JN, Antoni M, Ironson G, Ishii M, Vaughn A, Cassells A, Jones D, Schneiderman N, Brondolo E, Laperriere A, Lopez M, Villar-Loubet O, Camille J, Kumar M, Page JB. 2011. Enhancing the health of women living with HIV: the SMART/EST Women's Project. International Journal of Women's Health 3: 63-77.

Whitelaw S, Baxendale A, Bryce C. MacHardy L, Young I, Witney

E. 2001. 'Settings' based health promotion: a review. Health Promotion International 16: 339-353.

Yahiaoui A, McGough EL, Voss JG. 2011. Development of evidence-based exercise recommendations for older hiv-infected patients. Journal of the Association of Nurses in AIDS Care 23:

204-219. 